\title{
A Study of Humerus Bone of Nepalese Origin
}

\author{
Rajeev $M^{*}$ and Powar BP \\ Department of Anatomy, Manipal College of Medical Sciences, Pokhara, Nepal \\ *Corresponding author: Dr. Rajeev Mukhia, Department of Anatomy, Manipal \\ College of Medical Sciences, Fulbari, Pokhara, Nepal, Tel: 00977-9845100285, \\ Email: Rajeev510@yahoo.com
}

\section{Editorial \\ Volume 2 Issue 3}

Received Date: October 24, 2018

Published Date: November 30, 2018

DOI: $10.23880 /$ jhua- 16000133

\section{Abstract}

Introduction: Anthropometric techniques have been commonly used to estimate the stature from bones and play an important role in identifying unknown bodies by anthropologists and anatomists for over hundred years. The morphometry of humerus, number and location of nutrient foramina are variable between different individuals with different Nationality.

Aim: The aim of this study was to study the morphometry of adult humeri of Nepalese subjects.

Materials and Methods: The present study was carried out on 60 adult humerus bones of both sides. Maximum length of humerus, circumference at the middle of shaft and position of nutrient foramen was measured and recorded separately for both humeri with the help of measuring scale, thread and vernier calliper. All the collected data were represented as mean then analyzed with MS Excel 2007 software and represented graphically.

Observations and Results: Maximum length of humerus was 29.38 and $30.3 \mathrm{~cm}$ for right and left humeri respectively. The single nutrient foramen was present in $86.66 \%$ and $80 \%$ of right and left humeri respectively double nutrient foramina in $13.33 \%$ and $16.66 \%$ of right and left humeri respectively. Triple nutrient foramina were not seen in right humeri where as it was seen in $3.33 \%$ of left humeri.

Scope of Study: The parameters measured in the present study might be helpful to the anthropologists and orthopedic surgeons during any surgical procedures such as bone repair, bone graft, microvascular bone surgery.

Keywords: Humerus bone; Morphometry; Nutrient foramen; Nepalese subjects

\section{Introduction}

The humerus is the bone of the arm, and is the strongest and longest bones of the upper extremity. It presents upper and lower ends, and an intervening shaft [1]. Nutrient foramen is an opening in the shaft of humerus. The nutrient artery enters through nutrient foramen through cortex into the medullary cavity of the humerus [2]. It is usually single in number and located on the antero-medial surface of the humerus close to the midpoint of medial border [3]. The number and location of foramina are variable and may alter during the growth of long bones [4].

Anthropometric techniques have been commonly used to estimate the stature from bones and play an important role in identifying unknown bodies, part of bodies or skeletal remains by anthropologists, medical scientists and anatomists for over hundred years [5]. The knowledge of knowing the mean values of humerus 
segments is very important for anatomic and forensic science and helps the investigator to define the identity of skeleton [6]. Knowledge of the number and location of nutrient foramina is useful in certain surgical procedures [7].

The morphometry of humerus, number and location of nutrient foramina are variable between different individuals with different Nationality. Therefore, the aim of this study was to study the morphometry of adult humeri of Nepalese subjects which may be useful to anatomists, forensic experts and to the orthopaedic surgeons performing procedures involving bone grafts, fracture repair, joint replacement and vascularised bone microsurgery.

\section{Materials and Methods}

The present study was carried out on 60 adult humerus bones of both extremities, in the Department of Anatomy, Manipal College of Medical Sciences, Pokhara, from July 2018 to August 2018. Normal humerus used in this study was collected from the Osteology laboratory of anatomy. The humerus was retrieved from cadavers of Nepalese origin aged between 30 to 60 years with irrespective of sex. Humerus with any fracture or pathological abnormalities was excluded from the study.

The side determination was done for the entire humeri and following parameters were measured in the study:

1. Maximum length of humerus.

2. Determination of total length of the humerus was taken in $\mathrm{cm}$ as the distance between the superior aspect of the head and the most distal aspect of the trochlea of each humeri.

3. Maximum circumference at the middle of shaft of humerus.

4. Position of nutrient foramen.

Location and direction of nutrient foramen in relation with surface and zone were observed and noted. The position of foramina was divided into three types of zones as follows (Figure 1):

Zone I: from $0 \%$ to $33.33 \%$, the foramen was in upper one third of the bone.
Zone II: from $33.33 \%$ to $66.66 \%$, the foramen was in the middle one third of bone.

Zone III: from $66.66 \%$ to $100 \%$ the foramen was in the lower one third of bone.

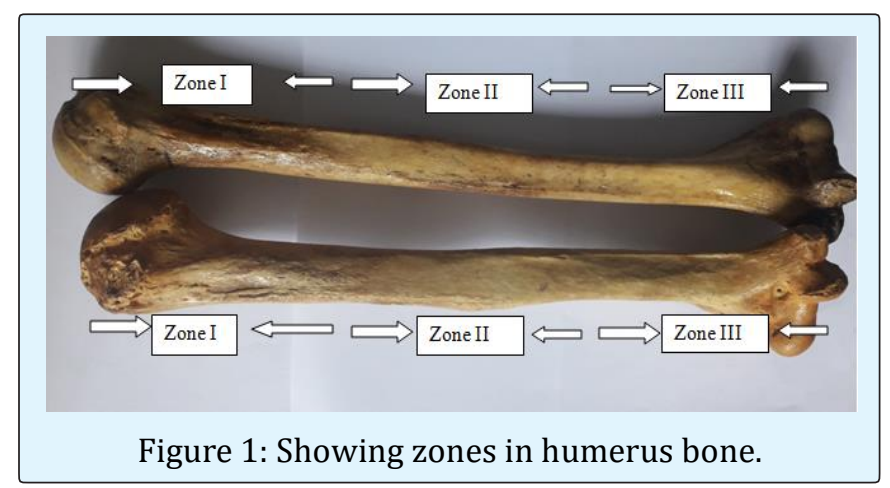

All the measurements are recorded separately for right and left humeri with the help of measuring scale, thread and vernier calliper. All the collected data were represented as mean then analyzed with MS Excel 2007 software and represented graphically.

\section{Results}

The following observations were found in the present study. The mean results and standard deviation (SD) of different parameters of both right and left humeri is summarized in table 1 and figure 2 . The nutrient foramina were found to be present in all humeri of both sides. The direction of nutrient foramina was not showing any deviation from normal anatomical feature even in single case throughout the study. All the foramina were directed downward or toward the lower end of humeri. The single nutrient foramen was present in $86.66 \%$ (26) of right humeri and $80 \%$ (24) of left humeri, double nutrient foramina in $13.33 \%$ (4) of right humeri and $16.66 \%$ (5) of left humeri. Triple nutrient foramina were not seen in right humeri where as it was seen in $3.33 \%$ (1) left humeri. It has been observed that a total of 34 nutrient foramina were found to be present in right humeri and 37 in left humeri. The majority of nutrient foramina was located in antero-medial surface of humerus where as few of them were located in posterior surface (Figure 3). The position and numbers of nutrient foramina of right and left humeri is summarized in table 2 .

\begin{tabular}{|c|c|c|c|c|c|}
\hline \multirow{2}{*}{ S.N } & \multirow{2}{*}{ Parameters } & \multicolumn{2}{|c|}{ Right humerus } & \multicolumn{2}{c|}{ Left humerus } \\
\cline { 3 - 6 } & & Mean in cm & SD & Mean in cm & SD \\
\hline 1 & Maximum length of humerus & 29.38 & 1.61 & 30.3 & 1.20 \\
\hline 2 & Maximum circumference at the middle of shaft & 6.38 & 0.23 & 6.12 & 0.17 \\
\hline 3 & Distance of nutrient foramina from upper end & 15.82 & 2.67 & 17.8 & 2.16 \\
\hline
\end{tabular}

Table 1: Showing mean and standard deviation (SD) of different parameters in $\mathrm{cm}$ of right and left humeri. 


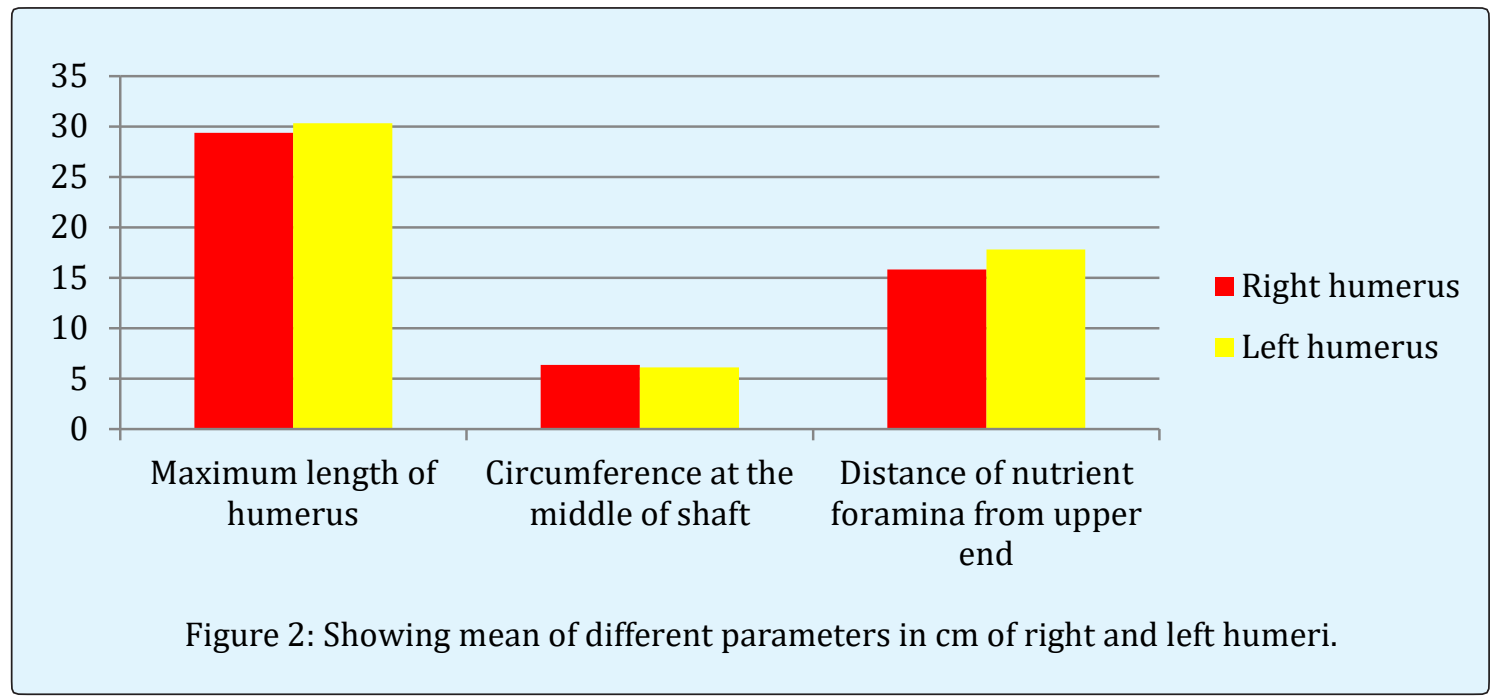

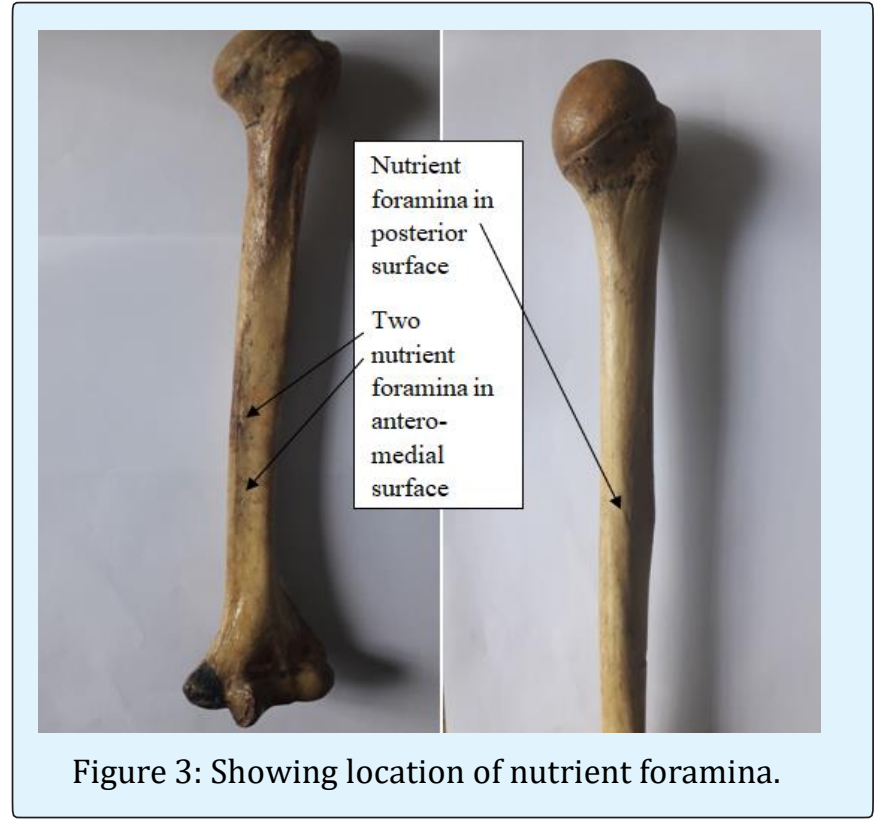

\begin{tabular}{|c|c|c|c|c|}
\hline $\begin{array}{l}\text { Position of } \\
\text { nutrient } \\
\text { foramen }\end{array}$ & $\begin{array}{c}\text { Right } \\
\text { humerus }\end{array}$ & $\begin{array}{c}\text { Number of } \\
\text { foramen in } \\
\text { right } \\
\text { humerus }\end{array}$ & $\begin{array}{c}\text { Left } \\
\text { humerus }\end{array}$ & $\begin{array}{c}\text { Number of } \\
\text { foramen in } \\
\text { left } \\
\text { humerus }\end{array}$ \\
\hline Zone I & 0 & 0 & 0 & 0 \\
\hline Zone II & 28 & 32 & 24 & 31 \\
\hline Zone III & 2 & 2 & 6 & 6 \\
\hline Total & 30 & 34 & 30 & 37 \\
\hline
\end{tabular}

Table 2: Showing position and numbers of nutrient foramina of right and left humeri.

\section{Discussion}

The knowledge of variations of nutrient foramina is significantly important for orthopaedic surgeons undertaking an open reduction of a fracture to avoid injuring the nutrient artery and thus lessening the chances of delayed or non-union of the fracture [8]. Intact arterial supply is very important for healing of a fractured bone [9]. Many studies reported high percentage of incidence of single foramina. A study done by Caroll, et al. in 71 humeri collected from University of Western Ontario, London and observed that $67.61 \%$ of humeri had a single nutrient foramen [10]. The incidence was found to be higher in a study conducted by Forriol, et al. [11] in 36 humeri collected from Medical School of Alcala de Henares University who reported the incidence of $75 \%$ of humeri with single nutrient foramen as compared to the present study. Similarly, a study conducted by Peirera, et al. [12] reported the incidence of $88.5 \%$ in Southern Brazil and Bhatnagar, et al. [13] reported the incidence of $90 \%$ of humeri with single nutrient foramen in Uttar Pardesh (India). The present study showed that single nutrient foramen was present in $83.33 \%$ of humeri.

A low percentage of incidence of single foramina (60\%) was reported by Shaheen [14] in Saudi Arabia, Mysorekar, et al. [7] (58\%) in Indian population and Joshi, et al. [8] (63\%) among Gujarati population. The present study showed that the prevalence of double nutrient foramina were found in $15 \%$ of humeri which was similar to the findings observed by Halagatti, et al. (17.5\%) studies [15]. Carroll in London reported $28.16 \%$ of humeri have double nutrient foramina [10]. Similar studies conducted by Bhatnagar, et al. [13] who reported 7.14\% of humeri, and Solanke, et al. [16] (4\%) found a 


\section{Journal of Human Anatomy}

lower incidence of double foramina in humeri to that of present study.

The present study showed that the majority of nutrient foramina $(86.66 \%)$ were found to be present in the middle one-third (zone II) of the shaft of the humeri which was correlated with the study conducted by Khan, et al. who reported $96.20 \%$ of nutrient foramina on the middle one-third of humeri of Pakistan cadavers [17].

In the present study the mean length of the humerus was calculated as $29.84 \mathrm{~cm}$ and is comparable more or less to that of studies done by Somesh, et al. [18] and Chawla, et al. [19].

\section{Conclusions}

The parameters measured in the present study might be helpful for the anthropologists and orthopedic surgeons during any surgical procedures such as bone repair, bone graft, microvascular bone surgery. In addition, the knowledge about the location of the nutrient foramina is important because of the increased chances of rupture to the nutrient artery during open or close procedures.

\section{References}

1. Elena FK, Markas B, Andrea SM, Antonio R (2009) A geometrc-morphometric study of the Cretan humerus for sex identification. Forensic Sci Int 189(1-3): 111 e1-e8.

2. Krishna G (2011) BD Chaurasia's Hand Book of General Anatomy. Blood supply of bones. 4th ed. CBS Publishers and Distributors Pvt. Ltd 43-44.

3. Standring S. Gray's Anatomy (2008), 40th ed. Churchill Livingstone Elsever 798.

4. Bokariya P, Gudadhe D, Kothari R, Murkey PN, Shende MR (2012) Comparison of humerus and femur with respect to location and number of nutrient foramina. Indian J Forensic Medi Pathol 5(2): 79-81.

5. Ozaslan A, Iscam MY, Ozaslan I, Harun T, Sermet K (2003) Estimation of stature from body parts. Forensic Sci Int 132(1): 40-45.

6. Mall G, Hubig M, Buttner, Kuznik J, Penning R, et al. (2001) A sex determination \& estimation of stature from the long bones of the arm. Forensic Sci Int 117(1-2): 23-30.

7. Mysorekar VR (1967) Diaphysial nutrient foramina in human long bones. J Anat 101(4): 813-822.

8. Joshi H, Doshi B, Malukar O (2011) A study of the nutrient foramina of the humeral diaphysis. NJIRM 2: 4-17.

9. Hoy WE, Hughson MD, Bertram JF, Douglas-Denton R, Amann K (2005) Nephron number, hypertension, renaldisease, and renal failure. J Am Soc Nephrol 16(9): 2557-2564.

10. Carroll SE (1963) A study of the nutrient foramina of the humeral diaphysis. J Bone Joint Surg 45: 176-181.

11. Forriol FC, Gomez LP, Gianonatti MA, Fernandez RV (1987) A study of the nutrient foramina in human long bones. Surg Radiol Anat 9(3): 251-255.

12. Pereira GAM, Lopes PTC, Santos AMPV, Silveira FHS (2011) Nutrient foramina in the upper and lower limb long bones: Morphometric study in bones of southern Brazilian adults. Int J Morph 29(2): 514-520.

13. Bhatnagar S, Deshwal AK, Tripathi A (2014) Nutrient foramina in the upper and lower limb long bones: A morphometric study in bones of western Uttar Pardesh. Int J Sci Res 3(1): 301-303.

14. Shaheen SY (2009) Diaphyseal nutrient foramina in human upper and lower limb long bones. A thesis submitted for the partial fulfillment of the requirement for the master degree in anatomy. 20-21.

15. Halagatti MS, Rangasubhe P (2011) A study of nutrient foramina in dry adult humerii of south Indian subjects. NJCA 1(2): 76-80.

16. Solanke KS, Bhatnagar R, Pokhrel R (2014) The number and position of nutrient foramina in humerus, radius, ulna of human dry bones of Indian origin with clinical correlation. OA 2(1): 1-8.

17. Khan AS, Shah Z, Inayat Q (2014) Anatomical variations in diaphyseal nutrient foramina of humerus in cadavers from khyber pakhtunkhwa, pakistan. Khyber Med Univ J 6(1):18-21.

18. Somesh MS, Latha VP, Shilpa K, Mangala MP, Ashwin K, et al. (2011) Morphometric study of the humerus segments in Indian population. Int J Morphol 29(4): 1174-1180.

19. Rahul R, Maheshwar C (2014) Morphometry of adult humerus bone in Moradabad region. Int J Bio \& Adv Res 5(3): 163-165. 